\title{
Southern Africa Labour and Development Research Unit
}

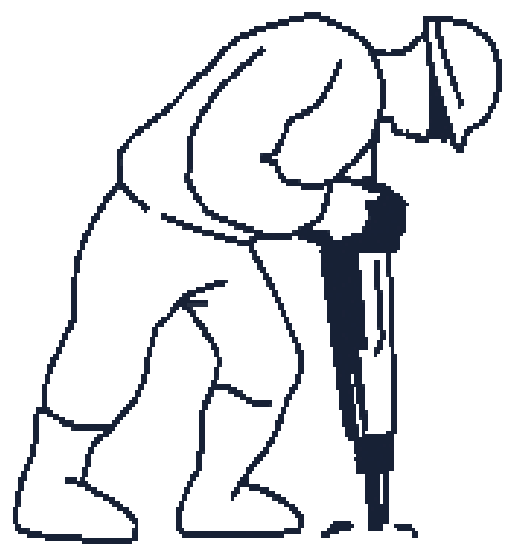

The effect of non-personnel resources on educational outcomes: Evidence from South Africa

Miquel Pellicer and Patrizio Piraino 
About the Author(s) and Acknowledgments

Miquel Pellicer, GIGA, Hamburg and SALDRU

Patrizio Piraino, University of Cape Town

We acknowledge funding from the EU's Seventh Framework Programme through the NOPOOR project: "Enhancing knowledge for renewed policies against poverty". We would like to thank participants at the SALDRU seminar at the University of Cape Town, and at the RP3 GIGA seminar for useful comments. We are grateful to Rob Garlick for detailed and very useful feedback on an earlier draft. All errors are ours.

Contact information for corresponding author: Miquel Pellicer, GIGA Institute of Middle East Studies, Neuer Jungfernstieg 21, 20354 Hamburg, Germany. Email: pellicer.miquel@gmail.com

\section{Recommended citation}

Pellicer, M., Piraino, P. (2015). The effect of non-personnel resources on educational outcomes: Evidence from South Africa. A Southern Africa Labour and Development Research Unit Working Paper Number 144. Cape Town: SALDRU, University of Cape Town

ISBN: 978-1-928281-05-4

(c) Southern Africa Labour and Development Research Unit, UCT, 2015

Working Papers can be downloaded in Adobe Acrobat format from www.saldru.uct.ac.za.

Printed copies of Working Papers are available for R20.00 each plus vat and postage charges.

Orders may be directed to:

The Administrative Officer, SALDRU, University of Cape Town, Private Bag, Rondebosch, 7701, Tel: (021) 650 5696, Fax: (021) 650 5697, Email: brenda.adams@uct.ac.za 


\title{
The Effect of non-personnel resources on educational outcomes: Evidence from South Africa*
}

\author{
Miquel Pellicer \\ GIGA, Hamburg and SALDRU \\ Patrizio Piraino \\ University of Cape Town
}

April 14, 2015

\begin{abstract}
Little credible evidence exists on the effect of material resources on school quality in developing countries. This paper studies the impact of non-personnel funding on educational outcomes exploiting the peculiar way in which these resources are allocated in South Africa. Government funding follows quintiles constructed on the basis of school poverty scores. This creates discrete jumps in the allocation of funding and we use a regression discontinuity approach to analyze its effects on school outcomes at the end of high school. Our results show a small but positive effect of resources on student throughput during the last years of high school, and on the number of students writing the matriculation exam. However, additional resources do not translate into a higher number of successful exams, leading to an overall negative effect on pass rates. We suggest that these findings may have to do with schools reacting to the per-pupil nature of funding.
\end{abstract}

\section{Introduction}

There is great interest amongst both academics and policymakers on the type of policies that ameliorate school quality. School output is typically considered to depend on both the resources a school has at its disposal (e.g. infrastructure, teachers) as well as on the management and incentive structures faced by teachers and principals. Whereas most observers would probably agree that both types of factors matter, the emphasis appears to be moving towards incentives and management and away from resources (Bruns, Filmer, and Patrinos (2011)). A consensus seems to be emerging that resources may have a limited impact on student learning, particularly when distortions in management reduce their productivity (Hanushek (2006), Kremer and Holla (2009)). This argument is especially relevant for developing countries where distortions are likely to be more severe.

Nonetheless, the existing evidence on the effect of material resources on student learning in developing countries remains largely inconclusive. Glewwe, Hanushek, Humpage,

${ }^{*}$ We acknowledge funding from the EU's Seventh Framework Programme through the NOPOOR project: "Enhancing knowledge for renewed policies against poverty". We would like to thank participants at the SALDRU seminar at the University of Cape Town, and at the RP3 GIGA seminar for useful comments. We are grateful to Rob Garlick for detailed and very useful feedback on an earlier draft. All errors are ours.

${ }^{\dagger}$ Contact information for corresponding author: Miquel Pellicer, GIGA Institute of Middle East Studies, Neuer Jungfernstieg 21, 20354 Hamburg, Germany. Email: pellicer.miquel@gmail.com 
and Ravina (2011) undertake a thorough review of the literature on school resources and educational outcomes in developing countries. Interestingly, they differentiate between empirical studies with and without "credible" identification strategies. Most studies analyze the effect of specific inputs (such as the amount of teachers, blackboards, computers, etc.) with contrasting results. Glewwe et al. (2011) conclude that the body of evidence on each of these inputs remains too low for any strong conclusions. ${ }^{1}$

Perhaps even more surprisingly, virtually nothing is known on the effect of general nonpersonnel school expenditures. In the context of increasing management decentralization, schools are left to choose how exactly they spend their resources and a key concern for governments is on the effectiveness of funds transferred to schools. Besides some crosscountry studies that are likely to suffer from confounding factors, only two articles are cited in Glewwe et al. (2011) as dealing with the effect of these type of resources on school quality, (Nannyonjo (2007) and Du and $\mathrm{Hu}$ (2008)), neither of which uses what they consider "high quality" identification strategies. A credible identification strategy is probably important for this question as school resources are likely to be related to overall performance (e.g. via endogenous success in attracting funds or via government redistributive motives) and these would confound the "pure" effect of resources on quality. Partly as a result of the difficulties of estimating these effects from observational data, the findings from these studies are assessed by Glewwe et al. (2011) as "puzzling".

A recent paper by Das et al. (2013) does provide credible evidence on the effect of material non-personnel resources on test scores. These authors report the results from a randomized experiment in India where schools were assigned a block grant for nonpersonnel expenditures. They find a positive effect on test scores. These results, while extremely valuable, are based on an intervention with some distinct characteristics. The block grant was restricted to items to be used directly by students. Moreover, the method of disbursal required schools to make a list of desired items and had the implementing organization, together with the teacher, buy the items. These requirements may have prevented funds to be spent in grossly inefficient ways.

This paper evaluates the effect of non-personnel resources on educational outcomes on the basis of the actual policy for allocating such resources in South Africa. Evaluations based on existing government programs may offer a more realistic setting for studying the effect of material resources on student performance in developing countries. The peculiar manner in which these resources have been allocated since 2007 provides us with what we believe is a credible identification strategy. Schools are assigned a poverty score that depends on the socioeconomic characteristics of the surrounding community and divided into quintiles on the basis of this score. Non-personnel funding is then determined by the school quintile. Schools in the poorest quintile receive around 800 Rands ( $\sim 80$ USD) per pupil, while schools in the remaining quintiles obtain progressively less funding with schools at the top receiving about 150 Rands per pupil. Funding is therefore discontinuous in the poverty score at the thresholds determining the quintiles, and we use a regression discontinuity approach to estimate the effects of resources. Our main outcome variables are attendance and success in the national test that students take at the end of high school (matric).

\footnotetext{
${ }^{1}$ These questions have also been analyzed within the context of high-income countries. Jackson, Johnson, and Persico (2015) compare the adult outcomes of cohorts that were differentially exposed to school finance reforms in the U.S. and find a positive effect of increases in per-pupil spending on completed years of education and wages. Gibbons and Mcnally (2013) review the most recent wave of studies using quasi-experimental methods. They conclude that resources have an effect, although the range of estimates of their impact on student outcomes is rather wide. Also, these authors note that the role of resources may vary across schooling phases-i.e. early years, primary and secondary.
} 
In addition to having an allocation rule useful for identification, South Africa represents a particularly interesting case to study with regards to school resources and performance. Inequalities in both variables are massive in the country due to the historical legacy of discrimination against blacks and in favor of whites. Since the democratic transition of the first half of the 1990s, some of these inequalities have started to recede, although they remain very large. For instance, our data shows that in formerly whiteonly schools $54 \%$ of students obtain university-access pass rates, which compares with only $15 \%$ in formerly African black schools. Understanding the effect of resources on school outcomes will thus help assess the impact of progressivity in funding allocations on the "achievement gap" inherited from the past.

Our analysis will also be useful in light of current discussions on the potentially diverse effect of alternative resources. Cobb-Clark and Jha (2013) argue that different budget allocations across spending categories have distinct impacts on student achievement. Also, Glewwe and Kremer (2006) suggest that the political power of teachers might lead to a resource allocation with too much spending on teachers and too little on non-personnel inputs, which may result in a higher marginal product for the latter. Our paper can help inform this debate by adding empirical evidence on the marginal effect of a specific type of school spending: non-personnel resources. ${ }^{2}$

We use school-level data for five out of South Africa's nine provinces, totaling around 3,000 high schools. We have information on poverty scores, quintiles, enrollment by grade, as well as matric attendance and results. Our data are collected both before and after the current funding system, which was established in 2006/2007. Information before 2006 is used to verify the validity of our identification strategy as well as to control for pre-policy outcomes at the school level.

There are a number of challenges to our empirical approach. First, differences in funding across the bottom 3 quintiles are shown to be relatively small, leading us to exclude two of the four discontinuities we could potentially exploit. A second key challenge is that we generally do not observe overall school resources, but only the amount of funds provided by the government. This is problematic because high fees can render shocks to government funding unimportant. In addition, schools might compensate lower transfers from the government with higher fees. We check the soundness of our approach in light of these concerns by using more detailed data from one province, Gauteng, where we were able to obtain information on fees and a proxy for school non-personnel resources. Using the more detailed data from Gauteng, we find that the cut-off from quintile 3 to 4 is suitable for our analysis, and we rely exclusively on that jump for identification purposes. In particular, we find no evidence of fee compensation at that threshold.

We show a positive effect of resources on student throughput from grade 10 to $12 .^{3}$ Our results, however, provide no evidence of a positive effect of non-personnel resources on matric pass rates. If anything, the effects are somewhat negative. Taken together, our findings suggest that resources may have the effect of increasing the retention of academically weaker students. We speculate this might be a result of the per-pupil nature of funding, which may create an incentive to keep students past the compulsory level, with no effect on education quality (as measured by pass rates on the final examination). That is, we suggest that schools may respond to additional funding by altering their behavior

\footnotetext{
${ }^{2}$ It should be noted that there exist other funds at the provincial level in South Africa for capital upgrading (e.g. new classrooms or facilities). The type of funds on which our paper focuses should therefore be thought of as both non-personnel and non-capital.

${ }^{3}$ These are the post-compulsory grades in South Africa. Schooling is mandatory until grade 9 or age 15 (whichever comes first).
} 
on the incentivized margin (enrollment) but not on the non-incentivized margin (matric pass).

It is important to note, however, that our results apply to a specific type of schools, notably secondary schools just above the median of the school poverty distribution. It is plausible that resources might have a different (and positive) effect in other contexts. Notably, resources might be more productive in poorer schools (if decreasing returns are important) and/or in primary schools, where students are younger.

The rest of the paper is organized as follows. Section 2 explains the allocation of nonpersonnel funds across South African schools. Section 3 presents our empirical approach. After describing our data in Section 4, section 5 evaluates the strengths and limitations of the empirical strategy in our context. Section 6 presents the results while section 7 provides a discussion of the results and concludes.

\section{Allocation of non-personnel resources in South Africa since 2005}

Under the apartheid system, school allocations were highly regressive, with white students receiving substantially more funding than black students (Branson, Kekana, and Lam (2013)). After the democratic transition, the eradication of these inequalities became a priority. Salaries of black and white teachers were equalized. A progressive system for funding non-personnel expenditures was set up in 2000. These funds were meant to finance running costs of the schools, such as materials, small equipment, small repairs, etc. The system allowed high level of discretion to the provinces. Most of the funding followed what was denoted as the quintile system: each province constructed a poverty score that ordered schools from poorest to richest on the basis of the surrounding community and the characteristics of the school itself. The quintiles from this score determined the allocation that each school obtained. Funds assigned to each quintile varied significantly by province, as well as the amount of non-personnel resources channelled through the system ((Department of Basic Education, Republic of South Africa, 2003)).

In 2006 the scheme changed. It was observed that poorer provinces were allocating less resources to education than richer ones and the resulting amounts were considered not sufficient for certain schools. Therefore, the allocation rule became more centralized. A quintile system based on poverty scores still remained the basis for funding, but the quintiles were to be at the national, not the provincial level. As a consequence, the poverty scores were recomputed in a more homogeneous way across provinces. Importantly, the new scores were not allowed to account for school characteristics to avoid perverse incentives. The variables that formed the base for the poverty score were to be the same across all provinces: these included income, unemployment, and the level of education/literacy in the area. The geographic unit of analysis was to be the electoral ward, although some provinces appear to have used smaller units. ${ }^{4}$ Note that the provincial departments were given discretion on the weighting to apply to the various socioeconomic indicators. This, in addition to the fact that each province used a different scale, makes poverty scores not directly comparable across provinces. As detailed in the empirical section, poverty scores are interacted with provincial dummies when fitting the smooth function of the running variable in the RD model to account for these different scales.

\footnotetext{
${ }^{4}$ Wards are not administrative units in South Africa; the level of aggregation was dictated by the information available in the Census (Garlick (2013)). The national Department of Education provided each province with socioeconomic data from the 2001 Census.
} 
The reform of school funding also incorporated a change of the fee policy. Policymakers wanted to allow free access to school for poorer learners and the quintile system used for school funding was also used as a basis for fee waiving. Schools in quintiles 1 and 2 were declared "no fee schools" and therefore were not allowed to charge fees to students. The higher amount of resources these quintiles received by virtue of the funding system was considered enough to compensate for the lost fees. Starting in 2008, schools in quintile 3 also began to shift to a no-fee regime on a roll-out basis that varied by province.

For any given year, the government releases guidelines for funding to each quintile and the provinces decide on the actual disbursements. Wildeman (2008) indicates that some provinces deviated from the guidelines, although the differences do not appear to be significant. Figure 1 shows the evolution of funding for each quintile over time (in constant 2008 Rands). Quintiles 1 and 2 received around R700 per learner while the figures for quintile 4 and 5 are around R400 and R150. Values for all quintiles are relatively constant except for quintile 3, that increases from 2007 to 2010 from around R500 to R700. The change for quintile 3 reflects the change in the fee policy, with quintile 3 schools shifting to a no-fee regime over time. The figure also makes clear that the difference in funding between quintiles 1 and 2 and (from 2009 onwards) between quintiles 2 and 3 are relatively small, a point that will be relevant for our analysis below.

\section{Empirical approach}

We use a regression discontinuity approach to estimate the effect of school resources on educational outcomes. Since funding jumps at the poverty score thresholds that determine the quintiles, indicator functions of such jumps should in principle deliver the local causal effect of funding once we control for a smooth function of the poverty score. In our data, the quintiles that determine funding do not follow perfectly the poverty score: as time passes, a number of schools are assigned to different (typically lower) quintiles. The design is therefore fuzzy and leads us to adopt a standard IV approach using the original quintile assignment as instrument for resources. In our analysis, outcome and endogenous variables are averaged over the years 2008 to 2012.

More formally, consider an outcome $Y_{i j}$ of school $i$ in province $j$. Denote the funding received by each school by $F_{i j}$ and the poverty score associated to each school by $s_{i j}$. Because poverty scores differ by province, we will fit the smooth function of the poverty score separately by province, interacting the score with provincial dummies, denoted by $P_{j}$ for province $j$. The equation for the second stage is thus:

$$
Y_{i j}=P_{j} g_{j}\left(s_{i j}\right)+\rho F_{i j}+\beta^{\prime} z_{i j}+u_{i j}
$$

where $g_{j}$ is a flexible function of the poverty score, that is allowed to differ by province, and $z_{i j}$ is a vector of control variables. Notice that $\rho$, which is our coefficient of interest, is assumed not to differ by province, so that we obtain one coefficient that aggregates the effects across the different provinces.

$F_{i j}$ might be correlated with $u_{i j}$ because schools may succeed in attracting funds depending on political connections or general characteristics themselves linked with the performance of the school. For this reason, we instrument $F_{i j}$ with an indicator function that captures the original quintile assignment on the basis of the poverty score. If poverty scores were constructed using technical considerations, as argued above, the initial assignment (and therefore government funding) should be random around the threshold that determines quintile jumps. For reasons to be detailed below, our analysis is based on just 
one discontinuity, from quintile 3 to 4 and we focus on that discontinuity alone here. The indicator function taking value one for schools assigned to quintile 3 or less (as opposed to 4 or more) is denoted by $F 34_{i j}$. Our first stage is thus:

$$
F_{i j}=P_{j} h_{j}\left(s_{i j}\right)+\rho F 34_{i j}+\gamma^{\prime} z_{i j}+v_{i j}
$$

We estimate these equations by 2SLS. If no variable relevant for the outcome $Y$ jumps at the threshold defining the original quintile assignment $F 34_{i j}$, the error term $u_{i j}$ will be uncorrelated with the predictions of the first stage and $\rho$ will be consistently estimated. Because the poverty score is computed on the basis of geographical features, it is spatially correlated, and so are likely to be the outcomes we consider. We thus cluster our standard errors at the magisterial district level, a unit larger than the ward which typically served as the basis for the computation of poverty scores. There are 239 magisterial districts in our sample containing an average of 13 schools.

We estimate different specifications of these equations using alternative windows around the threshold for the jump from quintile 3 to 4 . The poverty score is centered around this threshold and standardized by dividing it by its standard deviation. The specifications we use are a polynomial of degree 3 for $g_{j}\left(s_{i j}\right)$ with a window of \pm 1.5 standard deviations, and a linear specification with a smaller window $( \pm 0.5)$ that allows for different slopes at either side of the threshold. Our benchmark specifications control for the apartheidperiod school classification and indicators for quintile jumps other than the one of interest from quintile 3 to $4 .{ }^{5}$ We also perform analyses with and without pre-2007 outcomes as controls.

The key challenge of the analysis is that we are interested in the effect of school resources but we only observe funding from the government. Specifically, we do not observe the fees charged by the school. This is problematic for several reasons. First, if government funding is only a minor component of school resources, differences in this type of funding will be practically insignificant. Secondly, schools may compensate lower government funding with higher fees. If this were the case, schools at either side of the quintile threshold would have smaller or no differences in resources compared to government funding alone, and this would bias our estimates towards zero. In addition, differences in fees at either side of the threshold could threaten the validity of our approach, since they would lead to a violation of the key assumption that $F 34_{i j}$ is uncorrelated with the error term $u_{i j}$ after controlling for a smooth function of the poverty score. In particular, differences in fees could imply that schools at either side of the threshold are different to start with, possibly through changes in the pool of students. We address these issues in section 5 below, after introducing the data in the following section.

\section{Data}

We use school level administrative data on five out of South Africa's nine provinces: Western Cape, Gauteng, Northern Cape, Eastern Cape and Kwazulu-Natal. These were the provinces from which we were able to obtain school poverty scores. The data come from different sources and have been merged by the authors. Poverty scores come from either the provincial Department of Education or from provincial Gazettes. They refer to the

\footnotetext{
${ }^{5}$ Some schools fall in quintiles other than 3 and 4 in the specifications with a large window. Omitting indicators for these other quintile jumps makes the first stage fit problematic for these specifications, since resources do change substantially at these other jumps. We thus include these indicators in all our regressions, although this makes no difference for our results beyond the first stage.
} 
years 2005 (Western Cape), 2006 (Eastern Cape), 2007 (Gauteng) and 2008 (KwazuluNatal and Northern Cape). These data have been merged with two administrative and freely available datasets on basic school characteristics. The first dataset is the national Department of Basic Education (DBE) EMIS information system, which provides data on school quintiles for different years and on the former apartheid-era school categorization (whether the school belonged to a white area, or an african black township, etc.). ${ }^{6}$ The second dataset is the SNAP survey, a school level survey with information on enrollment levels by grade for different years. ${ }^{7}$ In addition, these datasets have been merged with information on matric results obtained from the DBE. These include the number of students writing the exam and those passing for each school. All variables are available from 2008 to 2012. We also have enrollment data from 2003 to 2005 and matric information for 2005. Our analytical sample only includes schools for which we have information on all years, which are a large majority of them (83\%).

For one province, Gauteng, we obtained additional data from the provincial Department of Education, which we use to assess the robustness of our approach to a number of identification threats. The additional information for Gauteng includes the government non-personnel funding received by the school and, crucially, fee amounts at the school level. ${ }^{8}$ Moreover, the data from Gauteng contain information on the number of computers in the school as well as on the race composition of the student body. We use these variables as imperfect proxies of material resources owned by the school and students' socioeconomic status, respectively. Unfortunately, the available information is not constant across all years, so we use different subsamples in alternative estimations. In particular, fee information is available from 2008 to 2012, except for 2010. Information on the number of computers is available only from 2010 to 2012.

For the general dataset with all provinces, our funding variable is the amount of funds to be assigned to each school-on the basis of its quintile and province-as stated in the provincial official documents. It is important to note that this is based on the allocations that schools are supposed to obtain on the basis of the quintile reported in our data, not on the money they actually obtain. There are two possible sources of measurement error on this variable. First, the provincial documents and/or our quintile data could contain mistakes. In order to check for this possibility, we use the Gauteng data on the allocations to individual schools, which we have for 2008 and 2009. The correlation between the official Gauteng record and our funding variable is 0.90, suggesting that the extent of measurement error in this respect is fairly low. A second potential source of error may result from leakages in government disbursements, which would imply that schools receive less funding than they are entitled to. Reinikka and Svensson (2004) provide an example of this problem in Uganda. However, South Africa has a significantly better record of accountability in government expenses compared to other countries in the region. Also, since the information on the amount schools should receive is publicly available, this would not appear to be a major concern in our setting.

We take as treatment for time $t$ the average funding from the three years prior to $t$. This is because funding for learning is cumulative and funding at $t-1$ ought to contribute

\footnotetext{
${ }^{6}$ see http://www.education.gov.za/EMIS/tabid/57/Default.aspx

${ }^{7}$ See https://www.datafirst.uct.ac.za/dataportal/index.php/catalog/482

${ }^{8} \mathrm{~A}$ problem with the fee variable in the Gauteng data is the difficulty in distinguishing missing values from zeros. It seems that schools that charge no fees appear in the data with the fee variable missing. There are virtually no schools with fees coded as zero. In contrast, for instance in $2009,97 \%$ of schools in quintiles 1 and 2, which were not allowed to charge fees, have the fee variable missing. As a further confirmation of this assumption, the richest quintile (Q5) only has $5 \%$ of the schools with missing fees. We thus replace missing values with zeros in our sample.
} 
to learning as much as funding at $t .{ }^{9}$ The funding variable is expressed in R100s. This is the order of magnitude of the observed jumps in funding across quintiles and thus makes our IV estimates more comparable to the reduced form estimates.

Regarding our outcome variables, we focus on matric pass rates as well as on student throughput. The simple pass rate-i.e. the number of student passing the exam over those writing it-may not be the best measure of school performance. It is in fact possible that schools discourage low-achieving students from writing the test as a result of the emphasis placed on matric pass rates in a variety of accountability processes. ${ }^{10}$ For this reason, we also use as an outcome variable the number of student passing the examination relative to the number of pupils in grade 10 two years earlier. The other outcome variables are the student throughput from grade 10 to 12 and the ratio of students writing the matric exam relative to both grade 12 , and to grade 10 two years earlier.

Table 1 shows the descriptive statistics of our sample by quintile. We have from 500 to 700 high schools per quintile. ${ }^{11}$ As expected, the poorest schools are in the provinces of the Eastern Cape and Kwazulu-Natal, many of which belonged to the "homelands" under the apartheid regime. At the opposite extreme, in quintile 5, schools are predominantly White (and to a lesser extent Indian and Coloured) according to the old classification system. Quintiles 3 and 4 are more mixed, containing a significant number of township schools and with a more even distribution across all provinces (except Northern Cape, which is sparsely populated and has fewer schools in any quintile).

Table 1 also shows the treatment values as well as pre- and post-treatment outcomes. The treatment (government funding averaged between 2008 and 2012) indeed decreases with the quintile, showing small differences between quintile 1 to 3 and larger jumps between 3 to 5 . Almost all pre- and post-treatment variables (notably pass rates) increase by quintile, suggesting that poverty scores do reflect factors harmful for school progression and learning. Most patterns are clearly convex in quintile, with a particularly sharp difference between quintile five and the rest. This is consistent with expectations, reflecting the historical legacy of discrimination in South Africa and much in line with a variety of other socioeconomic outcomes (Leibbrandt, Woolard, Finn, and Argent (2010)). The throughput and pass rates for all quintiles, except the fifth, imply that during the period under analysis less than a third of students enrolled in grade 10 successfully completed matric two years later.

\section{$5 \quad$ Validity of the approach}

This section addresses potential concerns with our empirical approach before proceeding to the results. We start by addressing the concerns associated to not observing overall school resources in our data. We do this by providing evidence on schools in the Gauteng province for which we have additional information. We then use our main dataset from all provinces to assess the first stage of our model and to focus on the basic RD assumptions of no manipulation of the running variable and of no jump at the relevant threshold exhibited by pre-determined variables.

\footnotetext{
${ }^{9}$ The results are not affected by using funding for time $t$ only.

${ }^{10}$ Borkum (2012) also notes the possibility of "conscious gate keeping whereby schools block the progression of weak students at grade 10 in order to avoid having them eventually take the matric exams in grade 12" (p.376).

${ }^{11}$ The uneven number of schools across quintiles results from the under/over-representation of the five provinces in our sample in different quintiles.
} 


\subsection{Fees and government funding}

As mentioned above, the key challenge to our approach is that we cannot observe overall school resources, but only government funding. To explore the implications of this limitation for our analysis, we use data from the Gauteng province. These data include information on fees and material resources such as computers. We first assess whether jumps in government funding are economically significant and, secondly, whether it appears that fees are used to compensate for the discrete jump in funding. Since these issues apply to all schools and not only to secondary schools, we increase our sample size by using all schools in the province, although we also report results using secondary schools only.

Figure 2 shows average school fees by poverty score in Gauteng. The left panel includes all schools while the right panel considers only secondary schools. Each dot in the figure corresponds to the average from 2008 to 2012 (excluding 2010, for which no data is available) for the schools with a given poverty score. On average, each poverty score includes around 40 schools in the left panel and 12 high schools in the right panel. Vertical lines show the different quintile cutoffs. Richer schools (in higher quintiles) appear at low levels of the poverty score on the left side of the distributions.

There are two important messages from Figure 2. First, fees at richer schools are so large that dwarf any non-personnel government funding. While pupils in quintile 5 schools pay around 6000 Rand ( $~ 600$ USD) per year, non-personnel government funding in these schools is less than 200 Rands ( $\sim 20$ USD) per pupil. This is also true around the threshold between quintile 4 and 5 . This implies that the change in government funding at that threshold may be barely noticeable for the schools concerned, rendering that jump less attractive for identification purposes. Second, the figure shows how fees decrease very rapidly with poverty scores for quintile 4 schools, leading to no discernible differences in fees for schools at the right boundary of quintile 4 compared to schools at the left end of quintile 3 . This, together with the very limited jumps in government funding upon crossing quintiles 1 to 3 documented above, indicates that the only jump with potential for identifying the impact of school resources is the one from quintile 3 to 4 . This threshold appears particularly promising for our purposes since the poorest schools in quintile 4 charge very low fees (close to zero) as do the richest schools in quintile three, but receive significantly more government funding.

To formally assess the extent to which overall resources change upon crossing the different quintile thresholds, we add fees and government funding for each school to construct a measure of overall resources that can be used for running non-personnel expenditures. We then estimate the first stage in equation 2, separately for each jump. Table 2 shows the results. The first column considers all schools and uses a 3rd order polynomial and a relatively large window (1.5 standard deviations) around the cutoff. The second column uses a linear function with spline and a smaller window around the threshold ( 0.5 standard deviations). Columns 3 and 4 replicate the same estimations using only high schools. As expected, the only coefficients that are consistently large and statistically significant are those for the jump from quintiles three to four. ${ }^{12}$ Coefficients are in the order of 0.4 when all schools are used and slightly lower when only high schools are considered. This implies that quintile 3 schools close to this threshold obtain, on average, around 40 percent more resources than those at the other side of the threshold. This amount is thus both statistically and economically significant. As an illustration, Figure 3 shows the jump in

\footnotetext{
${ }^{12}$ The only other statistically significant estimate is a negative coefficient at the 2 to 3 threshold in column 1. However the estimate is not stable across specifications and appears on the whole to be both economically and statistically insignificant.
} 
log total resources upon crossing the different quintile thresholds fitting a linear function allowed to vary by quintile. Each dot in the figure again corresponds to the average of $\log$ resources for the schools with a given poverty score. The picture clearly shows that only the jump from 3 to 4 represents a genuine increase in overall resources.

Table 3 explores in more detail the jump in resources from quintile three to four in Gauteng. Different rows correspond to different outcome variables while the columns correspond to different specifications (and to using all schools as opposed to high schools) as in the previous table. For reference purposes, the first row reproduces the results of Table 2, using the log of total resources as outcome variable. We wish to assess if the jump in total resources posited by our administrative data is translated into a detectable jump in material resources owned by the school. The second row in the table thus uses computers per learner at the school as outcome variable. While there seems to be an increase in computers per learner upon crossing the threshold when considering all schools, no jump is discernible when using only high schools. This need not invalidate our approach because there can be reasons why high schools may not spend marginal resources on computers, but given that our analysis will focus on high schools, the fact that no jump in computers is apparent in these schools does raise questions on alternative uses of government funding and thus provide a word of caution when interpreting our results.

The third row in Table 3 uses as outcome variable average fees, in Rands, in order to test whether schools compensate lower government funding with higher fees at this threshold. Coefficients are generally small and never significant suggesting that the phenomenon of fee compensation is not so relevant for the schools we are considering. ${ }^{13}$ To further probe into this issue, the fourth row in the table considers whether the demographic profile of the student body jumps at the threshold. If schools do raise fees when receiving less government funding, we should observe a higher proportion of low-income students on the quintile 3 side. Because African blacks remain the poorest population group in South Africa, we use as (imperfect) proxy for the socioeconomic status of the student body, the proportion of African blacks among students in the post-treatment period. As shown in the table, there is no jump in this variable upon crossing the threshold. All in all, the patterns displayed in the bottom two rows of Table 3 do not seem to indicate that schools compensate lower government funding with higher fees.

In sum, the data from Gauteng provide us with valuable guidance regarding the validity of our approach. The jump from quintile three to four appears promising in the sense that it displays a substantial change of resources (although for high schools it does not translate into a higher number of computers). Moreover, fees at the schools around that threshold are close to zero and, indeed, we do not observe evidence of higher fees compensating lower government funds in these schools. We will thus proceed with our analysis for all provinces focusing on the jump from quintile 3 to 4 and using government funding as the endogenous variable.

\subsection{First stage}

Table 4 shows the jump in government funding from quintile four to three using all provinces. The first row considers the jump in the actual quintile. If quintiles followed the poverty score perfectly, the coefficient for this variable would be minus one. In our data the estimated coefficient is around -0.66 , showing that about one third of schools

\footnotetext{
${ }^{13}$ If anything, the coefficients are mostly positive, which would be the opposite of fee compensation. However, the estimates are somewhat unstable, possibly as a result of the fast exponential decline in fees in the relevant range (logs are not used because of the large amount of zeros).
} 
had their quintile reassigned relative to the original placement.

The second row uses as outcome our endogenous variable: government funding averaged over the previous three years. The jump from quintile four to three generates almost 200 additional Rands per pupil from the government. In log terms this implies an increase of around 0.35 to 0.4 points, very similar to the magnitudes observed for the jump in log income from the Gauteng data. This is reassuring and it strengthens the idea that fees do not appear to be very relevant for schools at this margin. The last rows in the table show that this result applies to different years. The increase is smaller for the last year of the sample period, indicating that schools have increasingly seen their assigned quintile recategorized over time.

\subsection{Poverty score manipulation}

In the process of designing the new poverty scores in 2005/2006, schools were allowed to contest their assigned poverty score. This introduces a risk of manipulation in our running variable. Wildeman (2008) documents findings from anonymous interviews with provincial officials involved in the creation of poverty scores. He reports that lobbying was quite limited in most provinces and that ad hoc adjustments were only made for schools near the boundaries of electoral wards (to account for possible discrepancies between the students' socioeconomic characteristics and those of the electoral ward). Garlick (2013) notes that the number of schools to be treated was chosen after the poverty scores had already been assigned, so that precise manipulation of the poverty scores in the neighborhood of quintile thresholds was not possible. It is also apparent from the first stage results above that provinces amended the initial quintile assignments for a significant number of schools over time, suggesting that much tampering was done ex-post. For these reasons, manipulation during the early poverty score assignments (our instrument) appears unlikely, although it cannot be completely ruled out, particularly for KwazuluNatal and Northern Cape for which our poverty score variable dates from 2008.

We thus follow standard practice in RD designs and check if there is a higher density of schools at the beneficial side of our threshold of interest (i.e. the quintile 3 side) relative to the costly side (the quintile 4 side). If schools have successfully manipulated poverty scores to their advantage we would expect such asymmetry. Figure 4 shows the distribution of poverty scores for schools in the neighborhood of the quintile 3 to 4 jump. There is no indication of an unusual amount of schools at the rightward side of the threshold, which corresponds to quintile 3 , relative to the leftward side. This suggests that manipulation of poverty scores should not be particularly concerning for our analysis.

\subsection{Balance at different sides of the threshold}

The critical assumption of our approach is that no variable relevant for school performance jumps at the quintile threshold (aside from non-personnel funding). Having addressed the possibility that fees may jump at the threshold, we now consider the question in a more general way, checking whether pre-treatment outcomes (i.e. outcomes before the current quintile system was introduced) are discontinuous at the threshold. If our approach is valid, the poverty score threshold determining quintiles ought to have been meaningless prior to the establishment of the current system and variables predating 2007 should not increase at that threshold.

Table 5 shows the jumps in pre-treatment outcomes at the 3 to 4 quintile cutoff. As in the previous table, each row corresponds to an outcome variable and each column to a different specification: either 3rd order polynomial with large window or linear with spline 
and small window. All regressions correspond to the "reduced form" where outcomes are directly regressed on the instrument. The first variable considered is the school quintile as it was in 2005. As mentioned above, poverty scores and quintiles existed and determined funding already before 2006, but they were calculated in a very different way. Our first goal is thus to test whether the former poverty score system generated a quintile jump in the same 'neighborhood' as the current one. As it is clear from the table, this is not the case, suggesting that the current quintile thresholds were indeed meaningless before 2007. The following rows use as outcome variables the pre-treatment outcomes. No coefficient is significantly different from zero at conventional levels in either specification. It appears that treatment groups are indeed "balanced" regarding factors relevant for school performance, and this suggests that our approach of focusing on the 3 to 4 quintile threshold is valid.

\section{$6 \quad$ RD estimates}

Table 6 shows the main results of our exercise: the estimates of the change in school outcomes upon crossing from quintile four to three. Column 1 shows the 3rd order polynomial specification with baseline controls (quintile jump indicator functions other than the one from 3 to 4, and Apartheid-era education department). Column 2 uses the same specification but adds the pre-2007 outcome as a further control. Columns 3 and 4 replicate the same models but use a linear specification with spline for the smooth function of the poverty score.

The first relevant result from table 6 is that coefficients are relatively small. No coefficient is larger than 0.025 , suggesting that the increase of about 200 Rands in funding per pupil resulting from the jump from quintile 4 to 3 (approximately 30 to 45 percent) has little impact on student outcomes. The second important result is that there are no positive effects of funding on the pass rate, a common indicator of education quality in the literature and a widely-used measure of high school performance in South Africa. Actually, the coefficients for matric pass rates appear to be quite reliably negative when using grade 12 enrollment as the basis for the ratio (row 4). The estimates are virtually zero when grade 10 enrollment is used in the denominator (row 6). This discrepancy appears to be driven by the positive effect of funding on student throughput from grade 10 to grade 12 (row 2) and, to a lesser extent, by the positive impact on writing the matric exam (row 5). At the same time, no discernible effect is apparent on grade 10 enrollment (row 1). In short, additional non-personnel funding appears to have no impact on grade 10 enrollment but increases throughput from grade 10 to 12 . The increase in throughput, however, does not translate into higher pass rates.

It is worth noting that these results are quite robust across specifications, with coefficients being relatively stable regardless of the polynomial/window used and whether pre-treatment outcomes are controlled for or not. The fact that the pre-treatment outcomes do not significantly affect the main coefficients provides a further assurance that the sample is indeed balanced on the pre-reform characteristics as discussed in the previous section.

\section{Discussion}

What can we make of the results shown in Table 6? One possible explanation is that schools react to the per-pupil nature of the funding policy, which increases the incentive to retain students past the compulsory grade/age. They may do this, for example, by 
being more lenient in allowing students to progress across grades. ${ }^{14}$ This would explain the positive effect of funds on throughput from grade 10 to 12 . To the extent that these 'marginal' students would have dropped out in the absence of additional funding, this may also explain the negative effect of resources on pass rates for grade 12 enrollees. One can assume that, at the drop-out margin, students are below average in terms of academic preparedness, which would be consistent with the zero effect of funding on pass rates when grade 10 is used as the basis for the ratio.

Our results rest on the assumption that no fee compensation takes place at the quintile 3 to 4 threshold. We corroborate this assumption with evidence from the Gauteng province. To the extent that this may not hold for the other provinces in the data, lower fees and the consequent increased access for poorer students may produce observationally equivalent results-i.e. positive effect on enrollment along with negative effect on pass rates. Although we cannot test the absence of fee compensation in other provinces, we note that our data show no increase in enrollment at grade 10 for treated schools. We believe this renders the alternative interpretation less plausible, as there are few reasons to believe that cheaper schooling would result in higher throughput to grade 12 but not in higher enrollment at grade 10 (which is the first year of non-compulsory schooling in South Africa)..$^{15}$

Taken together, our results raise doubts on the effectiveness of non-personnel funding in improving school outcomes in our setting. Although additional years of schooling are generally considered to be beneficial for youth, irrespective of final graduation, the South African literature on returns to education reports virtually no earnings returns to completing grades 10 and 11 (Keswell and Poswell (2004)). This would imply little or no positive effect of the funding policy on students outcomes through additional years of education. Moreover, the 'marginal' students who benefit from more years at school may be significantly different from the inframarginal students, leading to the possibility of negative externalities from changes in class size and peer composition. ${ }^{16}$

Nonetheless, we note that it would be inappropriate to conclude from our results that providing material resources to relatively poor schools, in contexts such as the one in South Africa, cannot and generally does not improve learning. In particular, our results regard the effects of a R200 ( $\sim 20$ USD) increase in per-pupil resources for secondary schools around the quintile 3-4 threshold. There are three major reasons why resources in other contexts could have a positive effect on learning. First, non-personnel resources may have a differential impact on school quality at different parts of the poverty score distribution. For instance, the productivity of additional inputs may be higher in the bottom quintile where the lack of resources is more severe and the baseline quality indicators are lower. Second, results could be different for primary schools where students, by virtue of being younger, may be more amenable to acquire additional cognitive skills (Heckman (2000)). Third, learning may be non-linear in resources. It is possible that complementarities between material inputs and indivisibilities imply that larger increases in resources have a proportionally higher impact than smaller increases.

\footnotetext{
${ }^{14}$ Gustafsson (2011) shows that failing a grade is one of the main correlates of student drop-out past grade 9 in South Africa. As mentioned above, there have been reports of conscious control of the progression of weak students at grade 10 (Borkum (2012)). The incentives of school principals and government officials with respect to student grade progression have also been noted in the media (http://mg.co.za/article/2011-03-11-matric-quality-vs-quantity).

${ }^{15}$ The absence of an effect on student enrollment at grade 10 is also at odds with the possibility that our results reflect a migration from untreated to treated schools in response to lower fees or a change in the perceived quality of education due to the increased available resources.

${ }^{16}$ We are grateful to Rob Garlick for pointing out these possibilities to us.
} 
Having said this, while our paper does not conclusively show that "resources do not matter" it does provide cautionary evidence regarding the potential for material resources to close achievement gaps such as the one observed in South Africa. In addition, our paper highlights the possibility that funding disbursed on a per-pupil basis may alter incentives on the subsidized margin.

\section{References}

Borkum, E. (2012). Can Eliminating School Fees in Poor Districts Boost Enrollment? Evidence from South Africa. Economic Development and Cultural Change, 60(2), 359-398.

Branson, N., Kekana, D., \& Lam, D. (2013). Educational expenditure in South Africa: Evidence from the National Income Dynamics Study. (Working Paper No. 124). Southern Africa Labour and Development Research Unit (SALDRU).

Bruns, B., Filmer, D., \& Patrinos, H. A. (2011). Making Schools Work : New Evidence on Accountability Reforms (No. 2270). The World Bank.

Cobb-Clark, D. A., \& Jha, N. (2013). Educational Achievement and the Allocation of School Resources (IZA Discussion Papers No. 7551). Institute for the Study of Labor (IZA).

Das, J., Dercon, S., Habyarimana, J., Krishnan, P., Muralidharan, K., \& Sundararaman, V. (2013). School inputs, household substitution, and test scores. American Economic Journal: Applied Economics, 5(2), 29-57.

Department of Basic Education, Republic of South Africa. (2003). Review of the financing, resourcing and costs of education in public schools. (Tech. Rep.). Pretoria.

Du, Y., \& Hu, Y. (2008). Student Academic Performance and the Allocation of School Resources: Results from a Survey of Junior Secondary Schools. Chinese Education and Society, 41(5), 8-20.

Garlick, R. (2013). How Price Sensitive is Primary and Secondary School Enrollment? Evidence from Nationwide Tuition Fee Reforms in South Africa [unpublished].

Gibbons, S., \& Mcnally, S. (2013). The Effects of Resources Across School Phases: A Summary of Recent Evidence (Discussion Paper No. 1226). Centre for Economic Performance (CEP).

Glewwe, P. W., Hanushek, E. A., Humpage, S. D., \& Ravina, R. (2011, October). School Resources and Educational Outcomes in Developing Countries: A Review of the Literature from 1990 to 2010 (NBER Working Papers No. 17554). National Bureau of Economic Research, Inc.

Glewwe, P. W., \& Kremer, M. (2006). Schools, Teachers, and Education Outcomes in Developing Countries. In E. A. Hanushek \& F. Welch (Eds.), Handbook of the economics of education (Vol. 2, pp. 945-1017). Elsevier.

Gustafsson, M. (2011). The when and how of leaving school: The policy implications of new evidence on secondary schooling in South Africa (Stellenbosch Economic Working Papers No. 9). Stellenbosch University.

Hanushek, E. A. (2006). School Resources. In E. A. Hanushek \& F. Welch (Eds.), Handbook of the economics of education (Vol. 2, pp. 865-908). Elsevier.

Heckman, J. J. (2000). Policies to foster human capital. Research in economics, 54 (1), $3-56$.

Jackson, C. K., Johnson, R. C., \& Persico, C. (2015). The Effects of School Spending on Educational and Economic Outcomes: Evidence from School Finance Reforms (NBER Working Paper No. 20847). National Bureau of Economic Research. 
Keswell, M., \& Poswell, L. (2004). Returns to Education in South Africa: A Retrospective Analysis of the Available Evidence. South African Journal of Economics, 72(4), 834-860.

Kremer, M., \& Holla, A. (2009). Improving Education in the Developing World: What Have We Learned from Randomized Evaluations? Annual Review of Economics, $1(1), 513-545$.

Leibbrandt, M., Woolard, I., Finn, A., \& Argent, J. (2010). Trends in South African Income Distribution and Poverty since the Fall of Apartheid. OECD Publishing.

Nannyonjo, H. (2007). Education Inputs In Uganda: An Analysis of Factors Influencing Learning Achievement in Grade Six (No. 6758). The World Bank.

Reinikka, R., \& Svensson, J. (2004). Local Capture: Evidence From a Central Government Transfer Program in Uganda. The Quarterly Journal of Economics, 119(2), 678704.

Wildeman, R. A. (2008). Reviewing Eight Years of the Implementation of School Funding Norms, 2000 to 2008 (IDASA). Pretoria. 
Figure 1: Evolution of per pupil funding by quintile

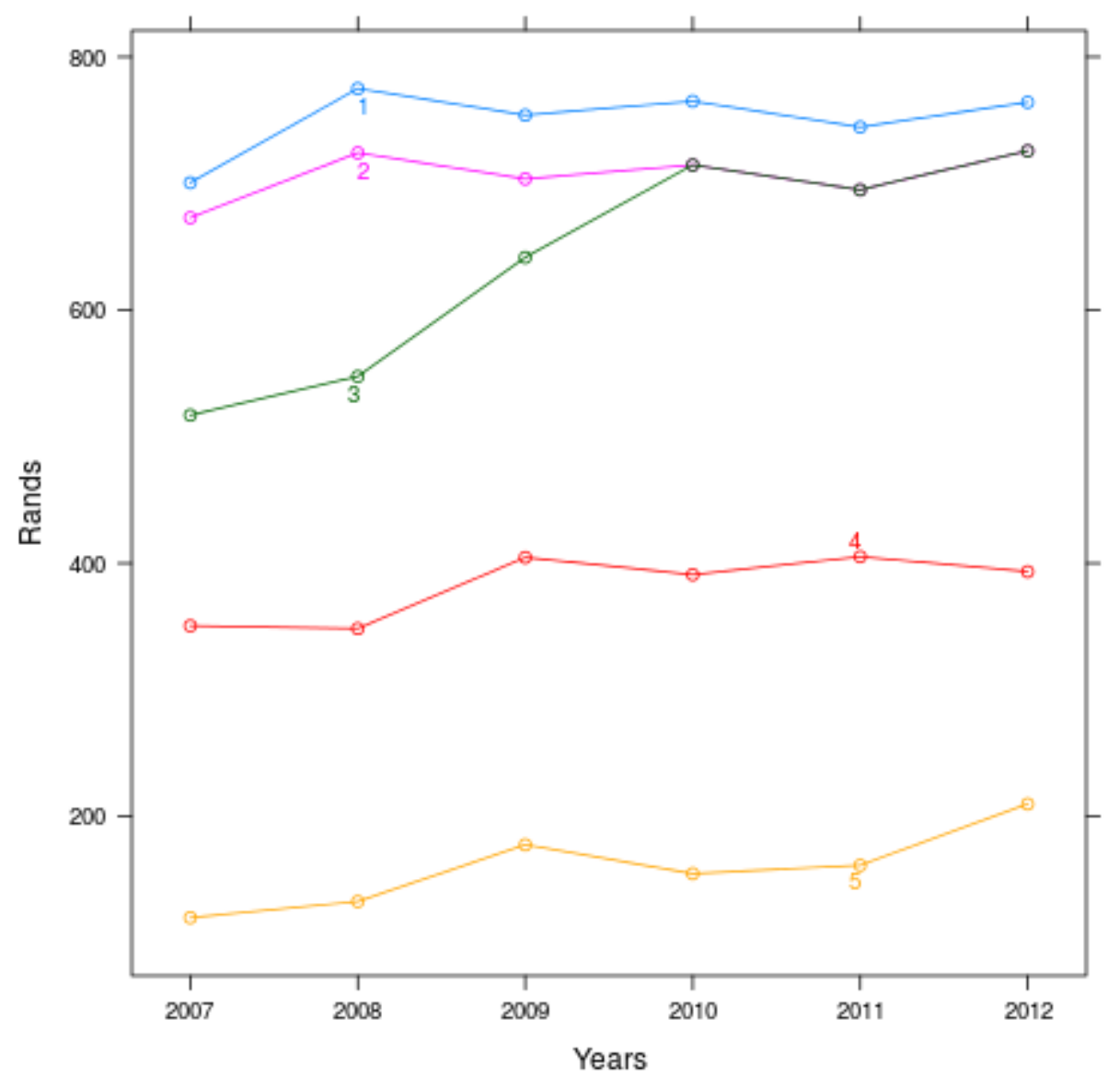


Table 1: Descriptive statistics by quintile

\begin{tabular}{|c|c|c|c|c|c|}
\hline Variables & Q1 & Q2 & Q3 & Q4 & Q5 \\
\hline \multicolumn{6}{|l|}{ Size } \\
\hline N_Schools & 550.00 & 536.00 & 754.00 & 520.00 & 446.00 \\
\hline \multicolumn{6}{|l|}{ Apartheid Department } \\
\hline townships & 0.10 & 0.16 & 0.32 & 0.30 & 0.04 \\
\hline coloured & 0.02 & 0.02 & 0.06 & 0.25 & 0.14 \\
\hline homeland & 0.68 & 0.64 & 0.48 & 0.18 & 0.02 \\
\hline indian & 0.00 & 0.00 & 0.01 & 0.09 & 0.18 \\
\hline natal & 0.03 & 0.04 & 0.03 & 0.04 & 0.03 \\
\hline new & 0.14 & 0.09 & 0.07 & 0.02 & 0.01 \\
\hline white & 0.01 & 0.01 & 0.02 & 0.12 & 0.57 \\
\hline \multicolumn{6}{|l|}{ Province } \\
\hline $\mathrm{EC}$ & 0.31 & 0.30 & 0.39 & 0.17 & 0.16 \\
\hline GT & 0.04 & 0.08 & 0.13 & 0.26 & 0.39 \\
\hline $\mathrm{KZ}$ & 0.61 & 0.56 & 0.39 & 0.38 & 0.32 \\
\hline $\mathrm{NC}$ & 0.01 & 0.02 & 0.02 & 0.03 & 0.01 \\
\hline $\mathrm{WC}$ & 0.03 & 0.04 & 0.06 & 0.17 & 0.11 \\
\hline \multicolumn{6}{|l|}{ Pre-treatment } \\
\hline log Grade 10 & 4.80 & 4.97 & 5.09 & 5.16 & 5.14 \\
\hline Throughput Grades 10-12 & 0.59 & 0.58 & 0.58 & 0.57 & 0.65 \\
\hline Matric attendance rate & 0.91 & 0.92 & 0.93 & 0.94 & 0.97 \\
\hline Matric pass rate & 0.61 & 0.62 & 0.61 & 0.66 & 0.83 \\
\hline Matric attendance rate over Grade 10 & 0.50 & 0.49 & 0.50 & 0.52 & 0.59 \\
\hline Matric pass rate over Grade 10 & 0.29 & 0.28 & 0.29 & 0.33 & 0.51 \\
\hline \multicolumn{6}{|l|}{ Treatment } \\
\hline Gov funding in R100s & 7.47 & 6.97 & 6.57 & 3.84 & 1.60 \\
\hline \multicolumn{6}{|l|}{ Post-treatment } \\
\hline $\log$ Grade 10 & 4.73 & 4.75 & 5.01 & 5.31 & 5.20 \\
\hline Throughput Grades 10-12 & 0.58 & 0.57 & 0.56 & 0.53 & 0.72 \\
\hline Matric attendance rate & 0.85 & 0.87 & 0.89 & 0.91 & 0.95 \\
\hline Matric pass rate & 0.59 & 0.62 & 0.62 & 0.74 & 0.89 \\
\hline Matric attendance rate over Grade 10 & 0.49 & 0.49 & 0.49 & 0.49 & 0.69 \\
\hline Matric pass rate over Grade 10 & 0.28 & 0.29 & 0.29 & 0.37 & 0.63 \\
\hline
\end{tabular}

Apartheid department refers to the government department managing different types of schools under Apartheid. The figures in these rows refer to the distribution of schools in different departments for a given quintile. Failure of the rows to sum up to one comes from missing values. Figures for treatment related variables correspond to the average in each quintile. Pretreatment variables refer to either 2005 (for matric variables) or to the average between 2003 and 2005 (for enrollment related variables). Posttreatment variables refer to the average between 2008 to 2012 . 
Figure 2: Average fees by poverty score, Gauteng province
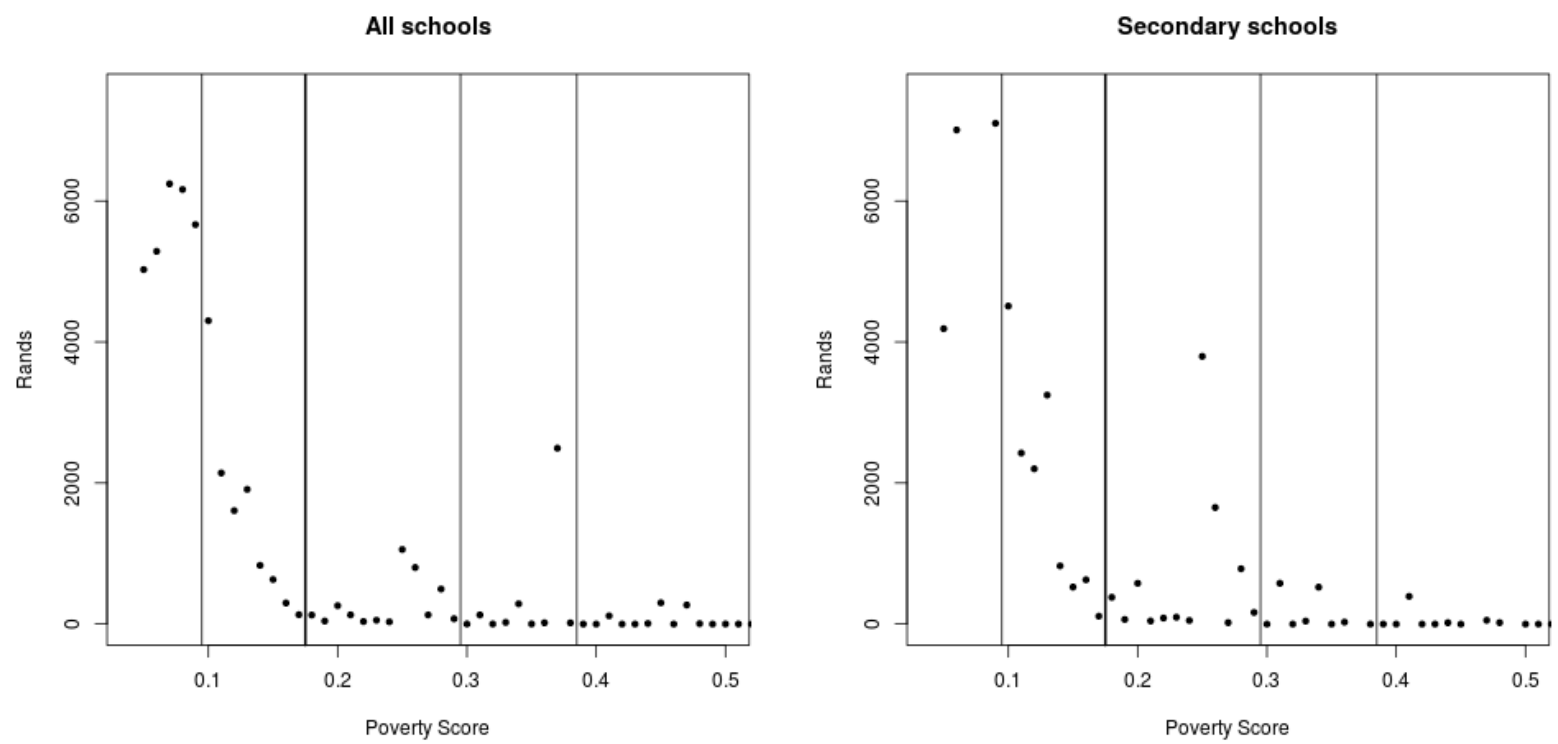
Table 2: Change in log total resources at different quintile jumps, Gauteng province

\begin{tabular}{lllll}
\hline & \multicolumn{1}{c}{1} & \multicolumn{2}{c}{2} & \multicolumn{1}{c}{4} \\
\hline & & & & \\
Indicator Jump 4-5 & -0.016 & -0.041 & 0.16 & 0.13 \\
& $(0.121)$ & $(0.124)$ & $(0.15)$ & $(0.15)$ \\
Indicator Jump 3-4 & 0.439 & 0.423 & 0.375 & 0.384 \\
& $(0.026)^{* * *}$ & $(0.028)^{* * *}$ & $(0.052)^{* * *}$ & $(0.051)^{* * *}$ \\
Indicator Jump 2-3 & -0.139 & -0.015 & -0.142 & -0.067 \\
& $(0.039)^{* * *}$ & $(0.021)$ & $(0.087)$ & $(0.081)$ \\
Indicator Jump 1-2 & -0.0023 & -0.029 & 0.089 & 0.102 \\
& $(0.0381)$ & $(0.055)$ & $(0.101)$ & $(0.095)$ \\
\hline & & & & \\
Sample & All schools & All schools & Secondary schools & Secondary schools \\
Poly.order & 3 & 0 & 3 & 0 \\
spline & 0 & 1 & 0 & 1 \\
N & 826 & 241 & 213 & 57 \\
\hline \hline
\end{tabular}

Robust standard errors in parenthesis. Signif. codes: $0.01^{(* * *)} 0.05^{(* *)} 0.1^{(*)}$. Coefficients from regressions corresponding to the reduced form from equations (1) and (2). Each coefficient corresponds to a separate regression where the outcome is always log total resources (fees+government non-personnel funding) and the instrument is the indicator functions for the corresponding jump in the row. The first two columns use all schools and the last two use only secondary schools. For each type of school, the first column uses a large window of 1.5 sd around the threshold, and the second column uses a small window of 0.5 sd with spline. 
Figure 3: Log Total Resources by poverty score, Gauteng province

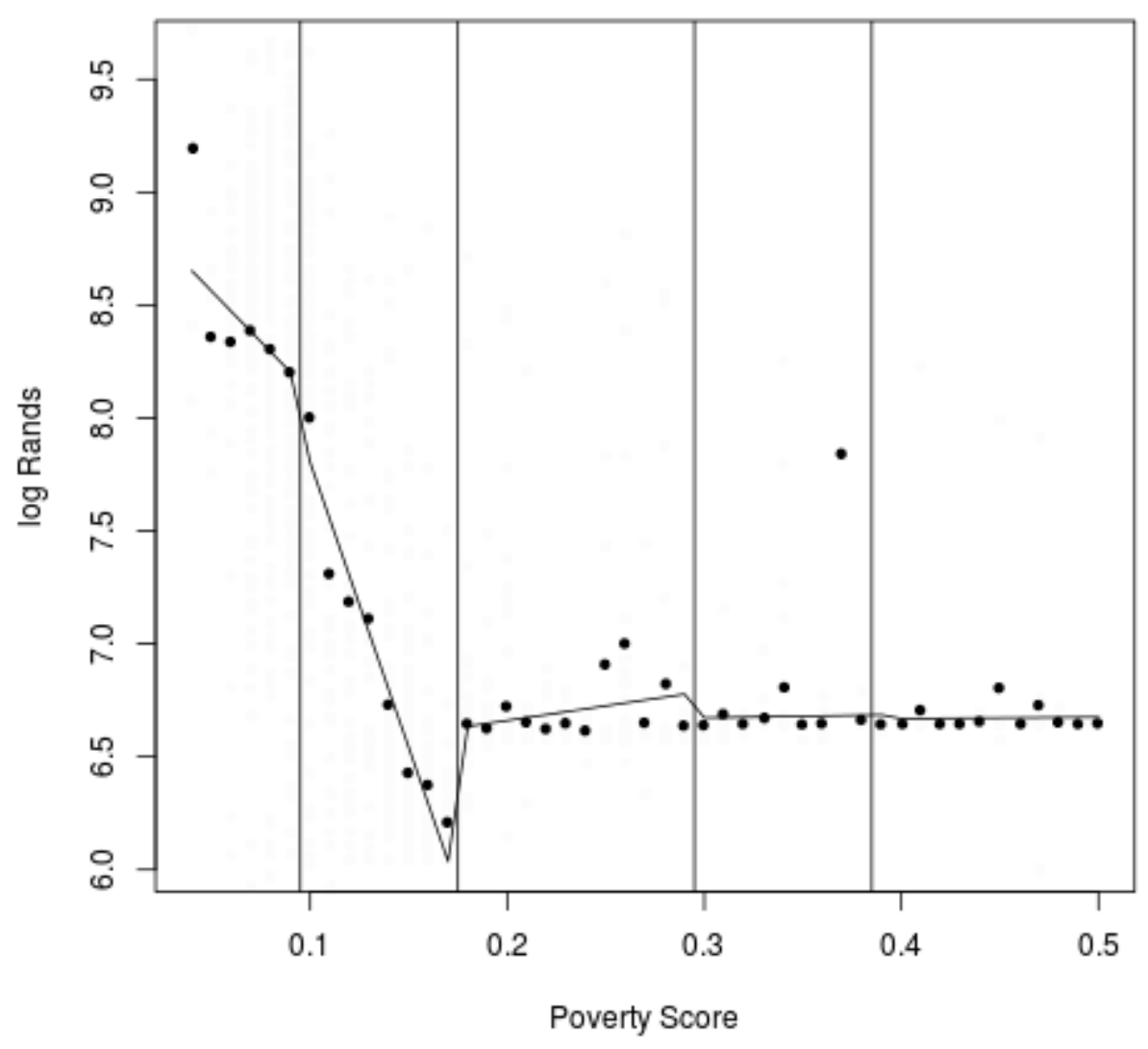


Table 3: Change in resource-related indicators at jump 3-4, Gauteng Province

\begin{tabular}{|c|c|c|c|c|}
\hline & 1 & 2 & 3 & 4 \\
\hline log total resources & $\begin{array}{l}0.439 \\
(0.026)^{* * *}\end{array}$ & $\begin{array}{l}0.423 \\
(0.028)^{* * *}\end{array}$ & $\begin{array}{l}0.375 \\
(0.052)^{* * *}\end{array}$ & $\begin{array}{l}0.384 \\
(0.051)^{* * *}\end{array}$ \\
\hline PCs per student & $\begin{array}{l}0.0117 \\
(0.0032)^{* * *}\end{array}$ & $\begin{array}{l}0.007 \\
(0.003)^{* *}\end{array}$ & $\begin{array}{l}-0.00061 \\
(0.00552)\end{array}$ & $\begin{array}{l}-0.0038 \\
(0.0050)\end{array}$ \\
\hline Fees & $\begin{array}{l}54.76 \\
(158.59)\end{array}$ & $\begin{array}{l}-97.17 \\
(120.66)\end{array}$ & $\begin{array}{l}250.17 \\
(225.06)\end{array}$ & $\begin{array}{l}75.22 \\
(94.51)\end{array}$ \\
\hline Percent African Black & $\begin{array}{l}0.0041 \\
(0.0117)\end{array}$ & $\begin{array}{l}0.0083 \\
(0.0138)\end{array}$ & $\begin{array}{l}0.0091 \\
(0.0190)\end{array}$ & $\begin{array}{l}0.016 \\
(0.024)\end{array}$ \\
\hline Sample & All schools & All schools & Secondary schools & Secondary schools \\
\hline Poly.order & 3 & 0 & 3 & 0 \\
\hline spline & 0 & 1 & 0 & 1 \\
\hline $\mathrm{N}$ & 1637 & 922 & 484 & 254 \\
\hline
\end{tabular}

Robust standard errors in parenthesis. Signif. codes: $0.01^{(* * *)} 0.05^{(* *)} 0.1^{(*)}$. Coefficients from regressions corresponding to the reduced form from equations (1) and (2). Each row uses a different outcome variable. PCs per student refer to the years 2010 to 2012. Fees refer to the years 2008 to 2012 , except for 2010. The first two columns use all schools and the last two use only secondary schools. For each type of school, the first column uses a large window of $1.5 \mathrm{sd}$ around the threshold, and the second column uses a small window of 0.5 sd with spline. 
Table 4: First stage: changes in quintile and government resources at jump 3-4, all provinces

\begin{tabular}{|c|c|c|}
\hline & 1 & 2 \\
\hline Quintile & $\begin{array}{l}-0.645 \\
(0.045)^{* * *}\end{array}$ & $\begin{array}{l}-0.67 \\
(0.05)^{* * *}\end{array}$ \\
\hline Gov funding & $\begin{array}{l}1.803 \\
(0.099)^{* * *}\end{array}$ & $\begin{array}{l}1.89 \\
(0.11)^{* * *}\end{array}$ \\
\hline log Gov funding & $\begin{array}{l}0.356 \\
(0.024)^{* * *}\end{array}$ & $\begin{array}{l}0.391 \\
(0.025)^{* * *}\end{array}$ \\
\hline $\log$ Gov funding 2008 & $\begin{array}{l}0.498 \\
(0.031)^{* * *}\end{array}$ & $\begin{array}{l}0.472 \\
(0.035)^{* * *}\end{array}$ \\
\hline $\log$ Gov funding 2010 & $\begin{array}{l}0.439 \\
(0.035)^{* * *}\end{array}$ & $\begin{array}{l}0.479 \\
(0.033)^{* * *}\end{array}$ \\
\hline log Gov funding 2012 & $\begin{array}{l}0.206 \\
(0.053)^{* * *}\end{array}$ & $\begin{array}{l}0.298 \\
(0.057)^{* * *}\end{array}$ \\
\hline Poly.order & 3 & 0 \\
\hline spline & 0 & 1 \\
\hline $\mathrm{N}$ & 2174 & 868 \\
\hline
\end{tabular}


Figure 4: Check of manipulation of running variable: Distribution of schools around the threshold, all provinces

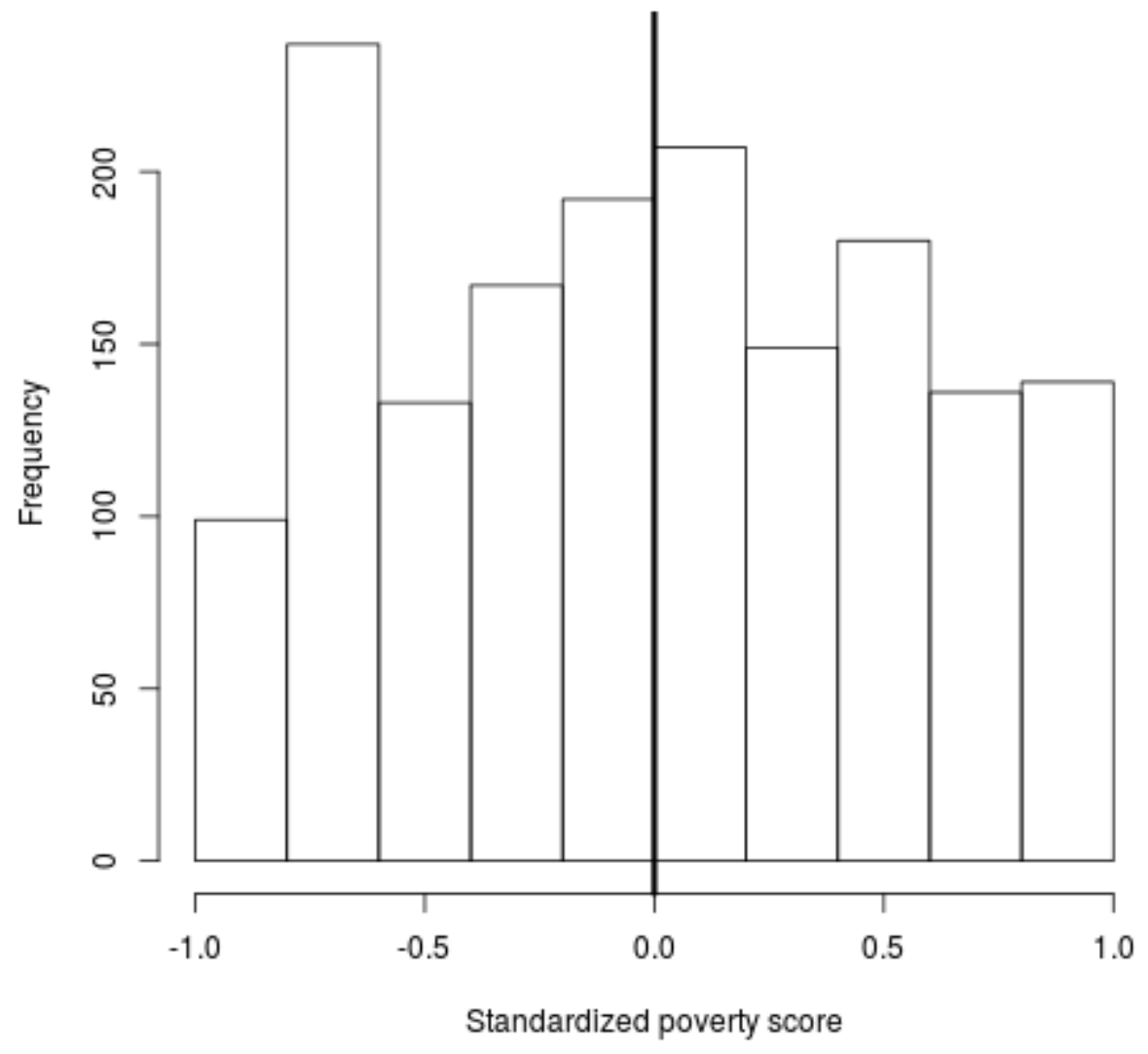


Table 5: Balance of pretreatment variables around jump 3-4, all provinces

\begin{tabular}{|c|c|c|}
\hline & 1 & 2 \\
\hline Quintile 2005 predet & $\begin{array}{l}-0.025 \\
(0.100)\end{array}$ & $\begin{array}{l}-0.11 \\
(0.12)\end{array}$ \\
\hline log Grade 10 predet & $\begin{array}{l}-0.051 \\
(0.058)\end{array}$ & $\begin{array}{l}-0.018 \\
(0.067)\end{array}$ \\
\hline Throughput Grades 10-12 predet & $\begin{array}{l}0.015 \\
(0.019)\end{array}$ & $\begin{array}{l}0.025 \\
(0.024)\end{array}$ \\
\hline Matric attendance rate predet & $\begin{array}{l}-0.0081 \\
(0.0114)\end{array}$ & $\begin{array}{l}0.0046 \\
(0.0139)\end{array}$ \\
\hline Matric pass rate predet & $\begin{array}{l}-0.032 \\
(0.022)\end{array}$ & $\begin{array}{l}-0.028 \\
(0.023)\end{array}$ \\
\hline Matric attendance rate over Grade 10 predet & $\begin{array}{l}-0.0016 \\
(0.0209)\end{array}$ & $\begin{array}{l}0.010 \\
(0.023)\end{array}$ \\
\hline Matric pass rate over Grade 10 predet & $\begin{array}{l}-0.0032 \\
(0.0163)\end{array}$ & $\begin{array}{l}0.00051 \\
(0.01816)\end{array}$ \\
\hline Estimation & $\mathrm{RF}$ & $\mathrm{RF}$ \\
\hline Poly.order & 3 & 0 \\
\hline spline & 0 & 1 \\
\hline $\mathrm{N}$ & 2144 & 853 \\
\hline $\begin{array}{l}\text { Robust standard errors in parenthesis. Signif. codes: } \\
\text { regressions corresponding to the reduced form from ec } \\
\text { outcome variable. Outcomes are different predetermin } \\
\text { of the new quintile system in } 2006 / 7 \text {. The quintile var } \\
\text { Enrollment variables use the average from } 2003 \text { to } 2005 \\
\text { around the threshold, and the second column uses a sm }\end{array}$ & $\begin{array}{l}0.01 \text { ‘*** } \\
\text { ations (1) } \\
\text { variables } \\
\text { ble and } n \\
\text { The first }\end{array}$ & $\begin{array}{l}.05^{\text {(**) } 0.1} \text { (*). Coefficients from } \\
\text { nd (2). Each row uses a different } \\
\text { measured before the establishment } \\
\text { tric related variables refer to } 2005 \text {. } \\
\text { lumn uses a large window of } 1.5 \mathrm{sd} \\
0.5 \text { sd with spline. }\end{array}$ \\
\hline
\end{tabular}


Table 6: IV results of post-treatment outcomes for jump 3-4, all provinces

\begin{tabular}{lllll}
\hline & \multicolumn{1}{c}{1} & \multicolumn{1}{c}{2} & \multicolumn{1}{c}{3} & \multicolumn{1}{c}{4} \\
\hline & & & & \\
log Grade 10 post & -0.016 & 0.0084 & -0.0082 & 0.00038 \\
& $(0.034)$ & $(0.0186)$ & $(0.0371)$ & $(0.02238)$ \\
Throughput Grades 10-12 post & 0.024 & 0.021 & 0.022 & 0.0160 \\
& $(0.012)^{* *}$ & $(0.011)^{* *}$ & $(0.012)^{*}$ & $(0.0096)^{*}$ \\
Matric attendance rate post & -0.0028 & -0.0017 & -0.0026 & -0.0032 \\
& $(0.0037)$ & $(0.0037)$ & $(0.0037)$ & $(0.0037)$ \\
Matric pass rate post & -0.0195 & -0.0134 & -0.0224 & -0.0182 \\
& $(0.0094)^{* *}$ & $(0.0083)$ & $(0.0095)^{* *}$ & $(0.0086)^{* *}$ \\
Matric attendance rate over Grade 10 post & 0.018 & 0.019 & 0.015 & 0.0149 \\
& $(0.010)^{*}$ & $(0.009)^{* *}$ & $(0.011)$ & $(0.0092)$ \\
Matric pass rate over Grade 10 post & 0.000054 & 0.0023 & -0.0025 & -0.0021 \\
& $(0.008532)$ & $(0.0058)$ & $(0.0090)$ & $(0.0062)$ \\
\hline & & & & \\
Estimation & IV & IV & IV & IV \\
Poly.order & 3 & 3 & 0 & 0 \\
spline & 0 & 0 & 1 & 1 \\
N & 2163 & 2138 & 866 & 852 \\
\hline R & & & \\
\hline
\end{tabular}

Robust standard errors in parenthesis. Signif. codes: $0.01^{(* * *)} 0.05^{(* *)} 0.1^{(*)}$. Coefficients from regressions corresponding to the IV from equations (1) and (2). Each row uses a different outcome variable measured after the new quintile system was established in 2006/7. Variables are measured as averages from 2008 to 2012. The first two columns use a large window of 1.5 sd around the threshold, and the second two columns use a small window of $0.5 \mathrm{sd}$ with spline. For each of these windows, the second column adds as further control the corresponding pretreatment outcome (ex. 2005 matric pass rate in row 4$)$. 


\section{southern africa labour and development research unit}

The Southern Africa Labour and Development Research Unit (SALDRU) conducts research directed at improving the well-being of South Africa's poor. It was established in 1975. Over the next two decades the unit's research played a central role in documenting the human costs of apartheid. Key projects from this period included the Farm Labour Conference (1976), the Economics of Health Care Conference (1978), and the Second Carnegie Enquiry into Poverty and Development in South Africa (1983-86). At the urging of the African National Congress, from 1992-1994 SALDRU and the World Bank coordinated the Project for Statistics on Living Standards and Development (PSLSD). This project provide baseline data for the implementation of post-apartheid socio-economic policies through South Africa's first non-racial national sample survey.

In the post-apartheid period, SALDRU has continued to gather data and conduct research directed at informing and assessing anti-poverty policy. In line with its historical contribution, SALDRU's researchers continue to conduct research detailing changing patterns of well-being in South Africa and assessing the impact of government policy on the poor. Current research work falls into the following research themes: post-apartheid poverty; employment and migration dynamics; family support structures in an era of rapid social change; public works and public infrastructure programmes, financial strategies of the poor; common property resources and the poor. Key survey projects include the Langeberg Integrated Family Survey (1999), the Khayelitsha/Mitchell's Plain Survey (2000), the ongoing Cape Area Panel Study (2001-) and the Financial Diaries Project.

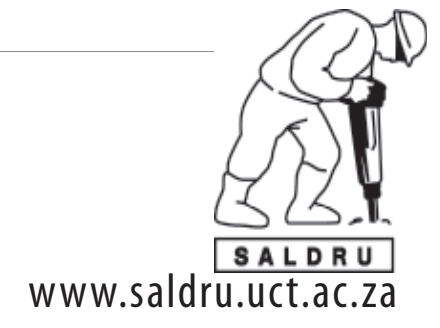

Level 3, School of Economics Building, Middle Campus, University of Cape Town

Private Bag, Rondebosch 7701, Cape Town, South Africa

Tel: $+27(0) 216505696$

Fax: +27 (0) 216505797

Web: www.saldru.uct.ac.za

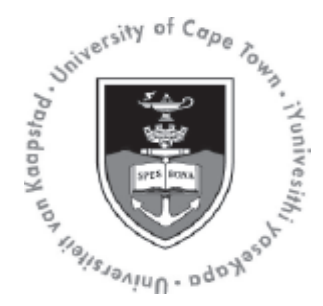

